\title{
A Study of Influence Factors of Syndication of Private Equity Investment Institutions in China
}

\author{
Lihong Wang, Baofeng Chen ${ }^{\text {a }}$ \\ School of Economics and Management, China Agricultural University, Beijing 100083, China \\ wlhworking@foxmail.com
}

Keywords: private equity investment; investment strategy; corporate growth

\begin{abstract}
Using data from January 1, 2000 to May 12, 2017 in PEdata, as well as Logit regression model and Poisson regression model, we examined influence factors of syndication from two aspects: private equity $(\mathrm{PE})$ investment institutions and invested firms. It was found that from the perspective of invested firms, early-stage firms were more likely to accept syndication than later-stage firms. Innovative firms were more likely to accept syndication. From the perspective of investment institutions, state-owned investment institutions were less likely to adopt syndication and state-owned investment institutions didn't play a regulatory role between the characteristics of invested firms and formation of syndication.
\end{abstract}

\section{Introduction}

As a form of investment of PE investment institutions, syndication often means that two or more than two PE investment institutions invest in the same firm [1]. Existing studies show that syndication helps investment institutions to diversify risks [2], share resources [3], optimize selection [1], increase value [4] and improve returns [5]. In developed countries, syndication is very prevalent in the PE industry [6]. In recent years, with the development of PE investment industry in China, syndication has become more and more common. According to data in China Venture Capital Yearbook 2014, among 45 valid samples surveyed in 2013, 88.89\% projects chose syndication. However, due to the limitations of data, there are very few empirical studies on the syndication of PE investment institutions in China. For this end, we used 25,589 investment cases from January 1, 2000 to May 12, 2017 in PEdata of Zero2IPO, to study influence factors of syndication of PE investment institutions in China.

\section{Literature Review and Hypotheses}

Existing studies on syndication are focused on syndication network [7], syndication partner [8-9] and syndication motivation [1-4], etc. From the perspectives of syndication network and syndication partner, some scholars point out that the syndication network [10], reputation and experience [11-13] and geographic proximity [14], etc. of investment institutions are likely to affect syndication. From the perspective of syndication motivation, some scholars point out that syndication is motivated by risk diversification, resource sharing and selection optimization, etc. [1-4] The risk [15], complexity [16] and innovation [17], etc. of invested firms may influence investment risk, demand for heterogeneous resources and further affect syndication.

To date, existing studies have failed to deliver consistent results about syndication. The author holds that there are two reasons for the disagreement and deficiencies of this issue: first of all, influence factors of syndication vary from area to area. Different conclusions can be attributed to regional differences between different data sources. Secondly, syndication involves many subjects and is affected by various factors. However, most of the existing studies only proceed from a single perspective. As an emerging market country in economic transition, the development of capital market and PE investment industry in China has a unique shape and path, making PE investment 
institutions in China show different characteristics. Below we will combine with existing studies and institutional background of PE investment in China, take the characteristics of invested firms and investment institutions into account and raise hypotheses.

\subsection{The effect of characteristics of invested firms on syndication}

According to the theory of life cycle, developmental stages of invested firms can be divided into seed, startup, expansion and maturity, etc. The earlier stage of invested firms, the less mature they are, the more uncertainty they are faced with, the greater information asymmetry when PE investment institutions evaluate their projects [16][18]. Syndication, however, can reduce information asymmetry between investment institutions and invested firms by sharing expertise, capital and social resources among investment institutions. Therefore, the earlier stage of invested firms, the more easily they get syndication. This conclusion has been also demonstrated by many scholars [16-18]. On the other hand, according to the financial view of motive theory of syndication, when a single investment cannot satisfy the demand of invested firms for huge capital, they will choose syndication [3]. The earlier stage of invested firms, the smaller size and funds they have, the weaker demand for syndication. Thus, we expect that the effect of the developmental stage of invested firms on syndication depends on the combined effect of the above two aspects. We don't raise a hypothesis in advance.

On the other hand, firms invested by $\mathrm{PE}$ investment institutions have another remarkable characteristic: innovative. When invested firms are innovative, investment institutions need to have more heterogeneous resources and value-added services, for example, expertise [17]. If invested firms are innovative, PE investment risks not only include new technical risks and market risks that invested firms are confronted with in their own development, but also decision and management risks caused by insufficient expertise of high-tech firms. Out of the need to diversify risks and provide value-added services, investment institutions tend to choose syndication. From this, we raise Hypothesized 1: the innovation of invested firms has a positive effect on syndication.

\subsection{The effect of state-owned background of investment institutions on syndication}

PE investment plays an important role in scientific and technological innovation and economic development. Some countries intervene in PE investment and establish state-owned PE investment institutions. In terms of ownership, PE investment institutions include two types: state-owned and non-state-owned. For a long time, state-owned PE investment institutions in China have occupied an important position in industrial pattern. They are different from non-state-owned investment institutions in investment behavior and performance [19][20]. This is because state-owned and non-state-owned investment institutions not only differ in investment and proprietor, etc., but also fundamentally differ in policy support and administration resources, etc. These differences lead to different abilities between two types of institutions to cope with institutional uncertainties and risks. Their coping strategies differ and lead to differentiated syndication between state-owned and non-state-owned investment institutions [20]. Compared with non-state-owned institutions, the effect of state-owned investment institutions on syndication is mainly manifested in the following aspects: (1) state-owned PE investment institutions are more inclined to independent investment, relying on their capital and resource advantages; (2) state-owned investment institutions have advantages in government resources and administration network, especially the acquisition of policy information and industry support information. They have favorable conditions to control and avoid risks during post-investment management, so they are more inclined to independent investment. From this, we raise Hypothesized 2: state-owned PE investment institutions have a positive effect on syndication.

On the other hand, since state-owned investment institutions have undertaken a policy task since their establishment- to lead PE fund to early-stage and innovative firms. Early-stage and innovative firms are confronted with greater risks and need more heterogeneous resources, so investment institutions are inclined to adopt syndication for such firms. Besides, the built-in resource advantage of state-owned investment institutions also attracts more syndication institutions. Therefore, to achieve the policy objective and resource complementation, state-owned investment institutions may 
adopt syndication. However, from the above hypothesis, state-owned investment institutions are reluctant to adopt syndication, because they can obtain high-quality projects, relying on information advantage and achieve higher returns in post-investment management using political resources. Meanwhile, some scholars point out that the role and effect that state-owned investment institutions in China have when guiding startups and high-tech firms are different [21]. From this, we expect that the effect of state-owned investment institutions on syndication when facing early-stage and innovative firms depends on the combined effect of the above aspects. We don't raise a hypothesis in advance.

\section{Research Design}

\subsection{Samples and data}

We selected PE investment cases (PE institutions-invested firms) from January 1, 2000 to May 12, 2017 as samples. Data were derived from PEdata of Zero2IPO (since data before 2000 in this database were added later, their reliability was in question, so we dropped data before 2000). Samples whose data were missing were ruled out. Finally, we got 25,589 investment cases by 10165 investment institutions in 22734 invested firms (here we used syndication in the narrow sense. The same investment by several PE investment institutions in the same firm was defined as a syndicated investment [22]. To eliminate the effect of subsequent investments on syndication, we only reserved the first investment case by each PE investment institution in the same firm.) Here, many PE investment institutions may syndicate investment in the same firm, but each investment case stood for an observation of match between a unique PE investment institution and an invested firm.

\subsection{Variable setting}

\subsubsection{The syndication of PE investment institutions.}

The explained variable in this paper were the syndication of PE investment institutions, including the "occurrence" and "result" of syndication. The occurrence of syndication was set as a dummy variable ( syn). If it occurred, $s y n=1$. If not, $\quad s y n=0$. The result of syndication was set as a scale variable ( nsyn), namely, the number of syndication institutions investing in the same firm.

\subsubsection{The characteristics of invested firms}

The characteristics of invested firms included developmental stage and innovation: according to whether invested firms were in early stages, a variable ( stage) was set. If invested firms were in early stages, $\quad$ stage $=1$. If not, stage $=0$ (in PEdata of Zero2IPO, invested firms were divided into four stages: seed, startup, expansion and maturity. In this paper, the first two stages were classified as early stages). The innovation of invested firms was measured indirectly according to whether invested firms were in high-tech industries ( ind $_{\mathrm{ht}}$ ). If invested firms were in high-tech industries, $\quad$ ind $_{\mathrm{ht}}=1$. If not, $\quad$ ind $_{\mathrm{ht}}=0$. (We defined high-tech industries with reference to Chen Minling (2013). Information technology, biotechnology, new energy and new materials, etc. were called high-tech industries. )

\subsubsection{State-owned background of investment institutions}

According to the background of investment institutions, a variable ( pe gov) was set. If PE investment institutions were state-owned (involving government funds or being funds or fund management agencies established by the government), $\quad \mathrm{e}_{\text {gov }}=1$. If not, $\quad \mathrm{pe}_{\text {gov }}=0$. To explore the combined effect of the background of PE investment institutions on syndication, we added the cross terms between state-owned background of institutions and characteristics of invested firms:

$$
\text { pe } e_{\text {gov }} * \text { stage and } \text { pe }_{\text {gov }} * \text { ind } \text {. }
$$




\subsubsection{Control variables}

To control the effect of other factors on syndication, we set the following control variables according to conclusions in relevant studies: investment scale ( inv $\left._{\mathrm{tos}}\right)$, represented by the total investment (millions of dollars) that invested firms got in Series A financing, a dummy variable ( region) representing the location of invested firms, i.e., if invested firms were in developed regions (regions where PE investment was concentrated, such as Beijing, Shanghai, Guangzhou, Shenzhen and Zhejiang), region $=1$; if not, region $=0$ and a dummy variable ( dist) representing the geographical relationship between invested firms and investment institutions, i.e., if invested firms and investment institutions were in the same province, dist $=1$. If not, dist $=0$.

\subsection{Modeling}

To test influence factors of syndication, we used Stata1 4.0 to conduct a regression analysis on data: when the explained variable syn was a two-valued variable, Logit regression analysis was adopted. When the explained variable nsyn was enumeration data, Poisson regression analysis was adopted. The regression equations are as follows:

$$
\begin{aligned}
& \operatorname{Logit}(\mathrm{syn})=\alpha_{0}+\alpha_{1} \text { stage }+\alpha_{2} \text { ind }_{\mathrm{ht}}+\alpha_{3} \mathrm{pe}_{\text {gov }}+\alpha_{4} \mathrm{pe}_{\text {gov }} * \text { stage }+\alpha_{5} \text { pe gov } * \text { ind }+\alpha_{6} \text { inv }_{\text {toa }}+ \\
& \alpha_{7} \text { region }+\alpha_{8} \text { dist }+\mu \\
& \text { Poisson }(\text { nsyn })=\alpha_{0}+\alpha_{1} \text { stage }+\alpha_{2} \text { ind }_{\text {ht }}+\alpha_{3} \text { pe }_{\text {gov }}+\alpha_{4} \text { pe gov }_{\text {gstage }}+\alpha_{5} \text { pe gov } * \text { ind }+\alpha_{6} \text { inv }_{\text {toa }}+ \\
& \alpha_{7} \text { region }+\alpha_{8} \text { dist }+\mu
\end{aligned}
$$

\section{Results and Analysis}

\subsection{Descriptive statistical analysis of variables}

Table 1 shows a comparison between the characteristics of invested firms and PE investment institutions in investment cases with and without syndication. Data showed that the total investment of non-syndication was smaller than that of syndication, which suggested that syndication can provide financial support. The stage and industry of invested firms, the background of investment institutions and whether they were in the same province, etc. were significantly different, while the region of invested firms was not significantly different between non-syndication and syndication.

Table 1 Comparison between Characteristics of Investment Samples

\begin{tabular}{c|c|c|c|c|c|c}
\hline & \multicolumn{3}{|c|}{ Mean } & \multicolumn{3}{c}{ Median } \\
\cline { 2 - 7 } & $\begin{array}{c}\text { Non- } \\
\text { syndic } \\
\text { ation }\end{array}$ & $\begin{array}{c}\text { Syndic } \\
\text { ation }\end{array}$ & Difference & $\begin{array}{c}\text { Non- } \\
\text { syndic } \\
\text { ation }\end{array}$ & $\begin{array}{c}\text { Syndica } \\
\text { tion }\end{array}$ & Difference \\
\hline stage & 0.36 & 0.33 & $(0.03)^{* * *}$ & 0.48 & 0.47 & $(0.01)^{* * *}$ \\
\hline ind $_{\mathrm{ht}}$ & 0.55 & 0.57 & $(-0.02)^{*}$ & 0.50 & 0.50 & $(0.00)^{*}$ \\
\hline pe $_{\text {gov }}$ & 0.16 & 0.13 & $(0.03)^{* * *}$ & 0.37 & 0.33 & $(0.04)^{* * *}$ \\
\hline inv $_{\text {toa }}$ & 8.35 & 13.72 & $(-5.37)^{* * *}$ & 17.93 & 21.4 & $(-3.47)^{* * *}$ \\
\hline dist $^{\text {disyyyyy}}$ & 0.62 & 0.66 & $(-0.04)^{* * *}$ & 0.49 & 0.47 & $(0.02)^{* * *}$ \\
\hline regio: & 0.67 & 0.69 & $(-0.02)^{*}$ & 0.47 & 0.46 & $(0.01)$ \\
\hline
\end{tabular}

Note: Differences in mean were tested with a two-tailed t-test. Differences in median were tested with a Wilcoxon rank sum test. ${ }^{*}, * *$ and ${ }^{* * *}$ meant that the results were two-tailed significant at the level of $0.1,0.05$ and 0.01 . 


\subsection{Results}

Table 2 Influence Factors of Syndication

\begin{tabular}{|c|c|c|c|c|c|c|}
\hline & Model 1 & Model 2 & Model 3 & Model 4 & Model 5 & Model 6 \\
\hline \multirow[t]{2}{*}{$\mathrm{inv}_{\text {toa }}$} & $0.260^{* * *}$ & $0.245^{* * *}$ & $0.266^{* * *}$ & $0.211^{* * *}$ & $0.200 * * *$ & $0.212^{* * *}$ \\
\hline & (28.95) & (29.31) & (29.37) & (38.97) & (39.52) & (39.33) \\
\hline \multirow[t]{2}{*}{ region } & $-0.174 * * *$ & $-0.128 * * *$ & $-0.164 * *$ & $-0.077^{* *}$ & $-0.052 * *$ & $-0.070 * *$ \\
\hline & $(-6.23)$ & $(-4.63)$ & $(-5.87)$ & $(-4.57)$ & $(-3.15)$ & $(-4.15)$ \\
\hline \multirow[t]{2}{*}{ dist } & $0.111^{* * *}$ & $0.128 * * *$ & $0.120 * * *$ & $0.097 * * *$ & $0.108^{* * *}$ & $0.102^{* * *}$ \\
\hline & (3.92) & $(4.55)$ & $(4.24)$ & $(5.50)$ & (6.10) & $(5.82)$ \\
\hline \multirow[t]{2}{*}{ stage } & $0.091^{* * *}$ & & $0.086^{* *}$ & $0.047^{* *}$ & & $0.047^{* *}$ \\
\hline & $(2.94)$ & & $(2.54)$ & $(2.42)$ & & $(2.25)$ \\
\hline \multirow[t]{2}{*}{ ind $_{\mathrm{h} 1}$} & $0.317^{* * *}$ & & $0.347 * * *$ & $0.182^{* * *}$ & & $0.195^{* * *}$ \\
\hline & $(11.24)$ & & (10.94) & $(10.21)$ & & $(9.94)$ \\
\hline \multirow[t]{2}{*}{$\mathrm{pe}_{\mathrm{gov}}$} & & $-0.411 * * *$ & $-0.335^{* *}$ & & $-0.259 * *$ & $-0.222 * *$ \\
\hline & & $(-12.26)$ & $(-5.72)$ & & $(-11.85)$ & $(-5.93)$ \\
\hline \multirow[t]{2}{*}{$\mathrm{pe}_{\mathrm{gov}}$ *stage } & & & -0.094 & & & $-0.086^{*}$ \\
\hline & & & $(-1.33)$ & & & $(-1.73)$ \\
\hline \multirow[t]{2}{*}{$\mathrm{pe}_{\mathrm{gov}} \times$ ind } & & & -0.081 & & & -0.029 \\
\hline & & & $(-1.17)$ & & & $(-0.63)$ \\
\hline \multirow[t]{2}{*}{ cons } & -0.325 & 0.066 & -0.237 & -0.105 & 0.124 & -0.058 \\
\hline & $(-1.64)$ & $(0.34)$ & $(-1.18)$ & $(-0.74)$ & $(0.87)$ & $(-0.40)$ \\
\hline Fixed effect of $y$ & Control & Control & Control & Control & Control & Control \\
\hline $\mathrm{N}$ & 25,589 & 25,589 & 25,589 & 25,589 & 25,589 & 25,589 \\
\hline Wald $\mathrm{chi}^{2}$ & 1242.21 & 1227.37 & 1369.60 & 2173.19 & 2198.90 & 2357.13 \\
\hline Prob $>L R c h t^{2}$ & 0.000 & 0.000 & 0.000 & 0.000 & 0.000 & 0.000 \\
\hline Pseudo $\mathrm{R}^{2}$ & 0.041 & 0.041 & 0.045 & 0.058 & 0.059 & 0.062 \\
\hline
\end{tabular}

Before regression analysis, we first conducted a collinearity analysis. It was found that the variance inflation factors (VIFs) of relevant variables were within an allowable threshold (VIF $<4$ ). The multicollinearity between variables was eliminated. Also, we ruled out the fixed effect of investment year.

Table 2 showed regression analysis results of influence factors of syndication, chi-square test statistics of 6 models ( Wald $\mathrm{chi}^{2}$ ) and corresponding $\mathrm{P}$ values, which suggested that all of the models passed the overall significance test. Models 1-3 showed Logit regression results and tested influence factors of the occurrence of syndication: first of all, Model 1 added control variables and characteristic variables of invested firms. Model 2 added control variables and state-owned background variable of investment institutions, pe gov. To investigate the combined effect of characteristics of invested firms and background of investment institutions on syndication, Model 3 added stage, ind $_{\mathrm{ht}}$ and pe gov and their cross terms. The results showed that the coefficients of stage and ind $\mathrm{ht}_{\mathrm{ht}}$ the main variables in Models 1 and 3 were significantly positive at the level of $1 \%$, which suggested that compared with later-stage firms, early-stage firms were more likely to syndicate investment. Since there were greater risks if PE investment institutions in China invested early-stage firms, it was necessary to syndicate investment. Compared with traditional industries, when invested firms were in high-tech industries, it was more likely to syndicate investment, because investment risks were greater if invested firms were innovative. It was necessary to syndicate investment. Hypothesis 1 was supported. The coefficient of pe $_{\text {gov }}$, the main variable in Models 2 and 3 were significantly negative at the level of $1 \%$, suggesting that state-owned investment institutions were less likely to syndicate investment than non-state-owned investment institutions. Hypothesis 2 was supported. Finally, none of the cross term results in Model 3 were significant, indicating that the characteristics of invested firms had no effect on the syndication of state-owned investment 
institutions. Models 4-6 showed Poisson regression results and tested influence factors of the result of syndication. The regression results of explained variables were roughly the same as in Models 1-3, except that the coefficient of $\quad \mathrm{pe}_{\text {gov }}{ }^{* \text { stage }}$, a cross term in Model 6 was significantly negative at the level of $10 \%$, suggesting that the syndication scale of state-owned investment institutions for early-stage firms was smaller than for later-stage firms, probably because early-stage firms had greater risks, but required fewer funds. State-owned investment institutions generally had more funds and higher affordability for small-fund investment risks of early-stage firms, so their syndication scale was smaller.

Note: $*, * *$ and $* * *$ meant that the results were significant at the level of $10 \%, 5 \%$ and $1 \%$ respectively. $1 \%$ one-tailed winsorization was conducted on inver. To save space, the regression results of year-controlled variables were not reported here.

\section{Conclusion and Implications}

In this paper, we study the effect of developmental stage and innovation of invested firms and background of investment institutions, etc. on syndication. It is found that compared with later-stage firms, early-stage firms are more likely to accept syndication. Innovative firms are more likely to accept syndication. Although early stages require fewer funds, similar to innovative firms, early-stage firms are faced with high uncertainty in the process of development and thus the investment risks are high. When investment institutions invest in early-stage firms and innovative firms, they need heterogeneous resources of multiple investment institutions to participate in project screening and post-investment management. In addition, we also find that compared with non-state-owned investment institutions, state-owned investment institutions can obtain high-quality projects, relying on information advantage and achieve higher returns in post-investment management using political resources. So they are less likely to adopt syndication. State-owned investment institutions don't play a regulatory role between the characteristics of invested firms and formation of syndication. That is, whether early-stage firms, firms in later stage, innovative firms or non-innovative firms don't have a significant effect on the syndication of state-owned investment institutions.

Our study shows that diversifying risks is a main reason for syndication of PE investment institutions in China. For high-risk early-stage firms and innovative firms, investment institutions are more inclined to adopt syndication. Since state-owned investment institutions have a built-in resource advantage and higher ability to control and avoid investment risks, there is no need for syndication. This suggests that state-owned investment institutions in China are underpowered to exert the guiding role of government. For high-risk early-stage firms and innovative firms, the syndication of state-owned investment institutions is not significant, either. This implies that state-owned investment institutions in China haven't played a guiding role through syndication.

\section{References}

[1] Lerner, J. The syndication of venture capital investments [J]. Financial Management, 1994, 23(3), $16-27$.

[2] Cochrane, John. The Risk and Return of Venture Capital [J].Journal of Financial Economics, 2005(75), 3-52.

[3] Brander J A, Amit R Antweiler W. Venture Capital Syndication: Improved Venture Selection VS the Value-Added Hypothesis [J].Journal of Economics \& Management Strategy, 2002, 11 (3), 422-451.

[4] Keil, T.,Maula, M.V., \&Wilson, C.. Unique resources of corporate venture capitalists as a key to entry into rigid venture capital syndication networks [J].Entrepreneurship Theory and Practice, 2010, 34(1), 83-103. 
[5] Gompers P A, Kovner A, Lerner J,et al. Performance Persistence in Entrepreneurship [J].Journal of Financial Economics, 2010, 96(1), 18-32.

[6] Deli D.N., Santhanakrishnan M. Syndication in Venture Capital Financing [J]. Financial R eview,2010,45(3),557-578.

[7] Bygrave W D. Syndicated investments by venture capital firms: A networking perspective [J].Journal of Business Venturing, 1987, 02(02), 139-154.

[8] Wang, Y.X., Dang X.H. and Wang X., Partner Selection in the Formation of Venture Capital Syndication: Resource Accumulation or Similarity Matching? [J] Science Research Management, 2015, (08), 144-151.

[9] Wang, X. and Wang Y.X., Research on Partner Selection of Venture Capital Syndication Based on the Social Network [J] On Economic Problems2013, (10), 24-29.

[10] Luo, J. and Dang X.H., Study on China’s VC Network Communities: Structure Recognition, Dynamic Evolution and Preference Features [J] Management Review, 2016, (05),61-72.

[11] Tykvova T. Who chooses whom? Syndication, skills and reputation [J].Review of Financial Economics, 2007, 16(1),5-28.

[12] Yang, M.L. and Dang X.H., Lead Venture Capital Firm Reputation, Investment Stage and Coinvestment Syndicate Composition [J] Forecasting, 2012(6): 21-27.

[13] Xue, C.K., Dang X.H. and Ren Z.Q., The Impact of Experience Signals on the Formation of Venture Capital Syndication [J], Science and Technology Management Research,2016, (21), 235-239.

[14] Douglas Cumming, Na Dai. Local Bias in Venture Capital Investments [J].Journal of Empirical Finance, 2010, 17,362-380.

[15] De Clercq D, Dimov D. Explaining venture capital firms’ syndication behavior: a longitudinal study [J].Venture Capital, 2004, 6(4), 243-256.

[16] Chen, M.L., Xue J. and Han J., An Empirical Study on the Complexity of Entrepreneurial Projects and the Reputation and Scale of Alliance of Venture Capital Investments [J] East China Economic Management, 2014,(09), 99-105.

[17] Chen, M.L., Dang X.H. and Xue J., Research on Mechanism of Project Novelty on

The Formation of Syndication in Venture Capital [J] Soft Science, 2013, (05), 16-20.

[18] Cai, N. and Xu M.Z., an Empirical Study on Investment Stage Selection of Chinese Venture Capital Institutions and Its Performance Effects [J]. China Industrial Economy, 2009, (10), 86-95.

[19] Y, Y., Luo W. and Li W. Z., Investment Behaviors and Performance of Government-sponsored Venture Capitals [J] Economic Research, 2014, (02), 32-46.

[20] Luo, J.D., Qin, L. and Zhou, L., Circle in Chinese Venture Capital Industry [J] Chinese Journal of Management, 2014, (04), 469-477.

[21] Shi, G. P., Dang X.H. and Dong, J.W., Could China's government venture capital guiding funds lead venture capital firms to invest in early-stage enterprises and high-tech enterprises: Empirical study with difference-in-differences model [J] Studies in Science of Science, 2016, (06), 822-832.

[22] Hochberg Y, Ljungqvist A,Lu Y.Whom you know matters: Venture capital networks and investment performance[J].The Journal of Finance,2007,62(1),251-301. 